\title{
Teaching outside the comfort zone: An overstated problem?
}

\author{
Laura Vang Rasmussen, Postdoctoral research fellow, International Forestry Resources \\ and Institutions (IFRI), School of Natural Resources \& Environment, University of Michigan, \\ US
}

\section{Reviewed article}

\section{Abstract}

Most teachers will eventually be assigned to teach topics that are outside their main area of expertise. In such situations, the teaching is often considered a major challenge. Lecture-based teaching has been framed as a survival strategy as teachers thereby can seek to control the classroom and avoid unforeseen questions from the students. However, limited literature exists on what can help make teaching efficient and comfortable when teachers have to teach outside their comfort zonether teaching styles have, however, largely been ignored and there is no consensus on how student learning is affected when teachers are working outside their comfort zone. To provide insight into the challenges and opportunities related to teaching outside the comfort zone, I refer to a pedagogical experiment from the 'Teaching and Learning in Higher Education Programme' offered by the University of Copenhagen. During this programme, I was assigned to teach a course that was outside my main specialization. Rather than turning to lecture-based teaching, I conducted a number of pedagogical activities including think-pairshare activities and role-play exercises. Based on these experiences, I argue that teachers should break away from the perception that lecture-based teaching is more comfortable. Even more importantly, I believe that teachers must shift their focus to student learning rather than their own performance.

\section{Teaching outside your specialty}

Every academic will eventually be asked to teach outside his or her specialization. Although this can prove rewarding and broaden the teacher's research horizons and experience of working with learners, recently graduated PhDs (in particular) can find the prospect daunting. When faced with such a situation many teachers turn to lectures as lecture-based teaching has been framed as a survival strategy that helps overcome some of the challenges that arise when teaching unfamiliar topics (Huston, 2009). For example, in a lecture-based setting, teachers can have greater control over the classroom than when using more interactive delivery techniques because they can avoid unforeseen questions from the students. While teachers may feel comfortable when lecturing, limited scientific literature exists on how teaching out- 
side the comfort zone and lectures as the primary choice of delivery mode affect student learning (Trigwell et al., 1999). In the sparse literature that does exist, there is no scientific consensus. While some scholars claim that being asked to teach unfamiliar material is a serious challenge for teachers - and students - (Huston, 2009), other scholars suggest that the problem is overstated (Merrill, 2012).

The present project seeks to provide insight into the challenges and opportunities related to teaching outside the comfort zone. The following two questions will be explored:

1. How can I - as an academic teaching outside my comfort zone - plan the teaching and learning activities so there is room for student-teacher interactions and unforeseen questions from the students without making the teaching an even greater challenge?

2. Do the evaluations from my students indicate that their experiences have been affected by my teaching outside the specialty?

In order to explore these questions, I will use my experiences from a course I was assigned to teach in 2014 at the Department of Geosciences and Natural Resource Management, University of Copenhagen. This course was outside my main specialization. When considering my planning for the course and facilitation of studentteacher interactions, I refer to the various pedagogical activities that I carried out during the course. These activities were planned in collaboration with my academic and pedagogical advisors, and the aim was to increase the student-teacher interaction. The planned activities included think-pair-share activities, role-play exercises and classroom discussions.

The assessment of these activities will be based on: 1) my own reflections on how the various settings worked for me when teaching outside my comfort zone, and 2) my advisors' observations as they were present during some of the sessions in which I tested the activities.

In order to consider the second question, the assessment of whether students experienced the teaching as being outside my specialty, I refer to the students' final evaluations of the course. These evaluations are quite general, and they do not go into detail about the individual teaching sessions. Nevertheless, they provide an overview of how students experienced the teaching and learning environment and they thereby give an indication of whether the problem with teaching outside one's specialization in fact is overstated - at least from the students' point of view. 


\section{Planning teaching outside the comfort zone: An example from a geography course}

Many scholars have argued that traditional lectures can result in limited student learning as students become very passive and their level of concentration drops after about 20 minutes (see e.g. Dahl and Troelsen, 2013). DeHann (2005) argues that traditional lecture settings most likely foster rote memorization, and not conceptual learning among students. One alternative to this traditional approach is to transform passive lecture classes into more student-centered, inquiry-based experiences. Despite the convincing evidence brought forward by DeHann (2005) and others, that this kind of approach fosters deeper understanding, I have been inclined to use the lecture style of information presentation for which I could (over)prepare and 'control' the setting. Lectures seem much more predictable than discussions and active learning, and this is attractve when you are teaching outside the comfort zone. When prompted to look at more interactive delivery methods, I found it important to plan the teaching in a way that allowed me to maintain some degree of this 'control'.

In a course that emphasizes student-centered learning the involvement of students can range from relatively brief activities (a few minutes) to lengthy apprenticeship projects continuing throughout the course. My advisors and I decided that I should try at least one brief activity and one of a more lengthy character. In the following, I will describe these two activities. Both can be done within a class session. While the first type of activity (Think-pair-share activity) can be included in a traditional lecture setting, the second type (role play exercise) changes the teaching-learning environment more fundamentally.

\section{Think-pair-share activities}

The think-pair-share activity has an estimated timeframe of 5-10 minutes, and it can be incorporated into a traditional lecture setting. The aim of this activity was twofold. Firstly, the idea was to switch the setting briefly from passive learning to more active learning by 'restarting students' attention clock' (Middendorf and Kalish, 1996). With this approach I could maintain a lecture setting, but punctuate the session with periodic activities.

Secondly, the activity was designed to 'disburden' my teaching. The students were encouraged to discuss and verbally articulate a given topic/text in pairs, and my role was to work from this base understanding and extend concepts if necessary. This exercise provided more opportunities for student-teacher interactions without making my job too much of a challenge. Moreover, the activity gave me a short 'break' in the lecture, which allowed me to run through my notes and see if I had remembered the most important points.

The activity ran as follows: 1) Students turned to someone near them, and they each chose a concrete example of the concept 'conventionalization of agriculture'. The 
concrete examples were given in a table in the curriculum; 2) Each student then explained the chosen example to their partner; 3) As the teacher, I randomly chose a few pairs to give a one minute summary of the examples; 4) I presented a 'validation slide' summarizing the main points about the concept 'conventionalization of agriculture'.

\section{Role play exercises}

A role play exercise with an anticipated timeframe of approximately one hour was also carried out. This activity aimed to provide a more substantial break from the information-delivering lecture. Also, it served to test whether I could find the feeling of control in a very different teaching-learning setting - a setting which has been claimed to be one of the teaching styles providing the teacher with the least amount of control (Nickerson, 2008).

One of the learning goals of the course I was teaching was that students should acquire skills to present scientific arguments for and against organic agriculture. In role-play situations students sometimes need to argue from viewpoints different to their personal preferences in order for them to become aware of the range of opinions on a particular subject. Thus, I found role-plays particularly helpful for supporting learning about the pros and cons of organic agriculture. A main challenge with this approach was, however, to maintain 'control'. My advisors suggested that I could account for the unpredictability of the discussions by focusing my background reading on the clearly formulated learning outcomes rather than trying to cover all conceivable topics and facets of organic agriculture. Moreover, I should prepare a few 'validation slides' with main arguments for and against organic agriculture. By doing so, I could control the final outcome of the class session - which I should regard as more important than controlling how the students would reach that outcome.

The role play ran as follows: 1) I divided all students (about 20-25) into two teams one team was pro organic agriculture, and the other team opposed organic agriculture (which might not necessarily reflected students' actual viewpoints); 2) The two teams had about 30 minutes to prepare a list of arguments representing their viewpoint; 3) Each team selected a spokesperson and a note taker; 4) A discussion between the teams took place, and as the teacher I called for a couple of timeouts during the discussion. These timeouts gave each team the possibility to discuss their line of argumentation, and how the spokesperson should proceed; 5) As soon as I sensed that the learning objectives had been met, I called the discussion to an end, and the note takers discussed their notes with the team; 6) In plenum, I summarized the main point of the discussion - this summary was based on my own observations of the discussion and the notes delivered by the two note takers. The discussion of notes within the teams and in plenary constituted the debriefing, which has been claimed to be one of the most important part of the role-play (Nickerson, 2008). 


\section{Evaluation of the teaching and learning activities}

\section{Think-pair-share activities}

My own reflections

The think-pair-share activity had the following advantages for me as a teacher: 1) it came as a welcome break; 2) I did not lose 'control' of the setting as there were no unforeseen questions; 3 ) it served as a good base for summarizing rather than explaining a complex concept and a table overloaded with information. Overall, this activity made the lecture more comfortable for me when teaching outside the comfort zone.

\section{My advisors' observations}

When the think-pair-share activity was initiated, my supervisors observed (from the back of the classroom) that it helped refocus the students' attention. Apparently some students had been checking emails and Facebook sporadically during the lecture. According to my advisors, the activity did not only have an engaging impact on the students during the 5-10 minutes it lasted - by switching the students' roles from passive to active. It also seemed to make the students more active during the rest of the lecture as they posed questions specifically related to the think-pair-share activity.

With these observations in mind, one could question what 'control' of the classroom actually entails. When I used to feel comfortable and in control of the classroom during a traditional lecture, it was obviously not control of student learning, but merely control of my own teaching. As argued by DeHann (2005), we must recognize that learning is a function of what the learner does, not the instructor. During a lecture setting, maintaining control becomes an issue of controlling the students' attention (Middendorf and Kalish, 1996). The argument about academics having more control of the classroom during a traditional lecture setting (when teaching outside their comfort zone) becomes thus somewhat invalid - if teachers only focus on own performance. Overall, planning of teaching outside the comfort zone should therefore include a focus on getting control of what students do rather than just focusing on getting control of the material being taught.

\section{Role-play exercises}

\section{My own reflections}

To gain a successful (and comfortable) outcome for the role-play exercise was anticipated to be more difficult than for the think-pair-share activity. This was primarily due to the prospect of breaking from the 'controlled' lecture format and the high level of student engagement required. In the event described above, the activity 
went smoothly, and the discussion between the teams could easily have continued if we had had more time.

As for my concerns about losing control, it turned out that I in fact ended up having possibly more control of student learning than I would have had in a traditional lecture setting. As the discussion between the teams progressed, I could compare the issues being discussed with my learning goals for the session. This was useful to get a sense of which knowledge students already mastered and the part of the curriculum that was not well understood. Such insight could then be used to adjust future teaching to better address identified knowledge gaps.

I assume that the successful outcome of the role-play was primarily a consequence of well-prepared students. Had the students not read the course material, I may have held a (for me) successful lecture with full control of the teaching, but rather limited control of student learning. To build on the earlier argument (about the need for including control of what students do during a session in our perceptions of control), one could claim that 'control' also is about controlling what students do before the actual class session.

To summarize, I would not consider this type of teaching a greater challenge than a traditional lecture setting - although the material being taught was outside my comfort zone. As my preparing for the class was focused around main learning outcomes (pros and cons of organic farming), it may even have taken less time than preparing a whole lecture. However, during the discussion between the teams a question was posed by a student, which I was not able to answer. This unforeseen question was clearly a consequence of the student-centered role-play exercise, but despite my irritation at not having the immediate answer; it does not outweigh the other advantages of the interactive session.

\section{My advisors' observations}

My advisors noted that the role-play really seemed to engage the students. In particular, it proved useful for supporting learning about the cons of organic agriculture a line of argumentation that some students prior to the class denied existed. The role-play, however, forced students to interact from the perspective of their role rather than from their own perspective on organic agriculture. During this interaction my advisors noted that the discussions were primarily based on the course material rather than students' perceptions of pros and cons.

As for the unforeseen question posed by a student, my advisors argued that as you grow in confidence, you will 1) not feel as uncomfortable saying 'I don't know the answer, but I'll try to find out the answer for the next session', and 2) have a better sense of which direction these unforeseen question might be heading to. 


\section{Students' experience of the teaching-learning environment}

In the following section, I will refer to the student evaluations of the course I was assigned to teach. As these evaluations did not focus on particular sessions and I never told the students that I was teaching outside my comfort zone, I will tease out any statements indicating 1 ) the effect of activities aiming at more student engagement, 2) that my concerns about teaching outside my specialty were overstated, 3) that my concerns were experienced by students.

Looking at the students' experiences of the teaching-learning format and the activities, one respondent mentioned that 'there were good discussions in which the students were heard and thereby became integrated in the teaching'. Another respondent wrote 'that there were many possibilities for critical discussions'. I regard these positive student responses as clearly related to the pedagogical activities,indicating that increased student activity did indeed have a positive effect on the students.

With regards to my concern about teaching outside the comfort zone, one respondent stated that the teacher was engaged, well qualified and well prepared, while another respondent noted that the teacher was good, inspiring and passionate. These statements indicate that my fear was somewhat overstated. However, it was also mentioned by one respondent that the teacher at certain times seemed a little insecure and that at these points some students took control of the situation. This points to the fact that finding a proper balance between student-centered and teachercentered activities is not an easy task - especially not when the teacher is outside the comfort zone. Moreover, the mention of student control is interesting in itself. Perhaps, particular students taking control of the learning is another issue that can be added to the list of concerns about relinquishing control when teaching outside the comfort zone.

With the above points raised in mind, a teacher delivering a course outside his or her comfort zone should still control 1) the material being taught, 2) the students' attention during the session, 3) the students' preparing before the session, and 4) the level of student control - i.e. too student-centered sessions may not be beneficial for all students.

To summarize, there is clearly a link between teacher thinking, the level of student activities and student learning outcomes. It is therefore pertinent for academics teaching outside their specialty to place the focus on the students rather than own performance. Although teaching outside the comfort zone often fosters traditional lectures and a perception of teaching as transmission of knowledge, the activities that I carried out have shown how more interactive teaching does not necessarily mean a greater challenge. While I set out to explore a setting in which the teaching was outside my area of specialization, the insight gained may also apply to other teaching settings. For example, teachers assigned to teach core areas of expertise 
may also regard more interactive teaching as a greater challenge, although it clearly does not need to be.

As teaching outside the comfort zone is highlighted as a common dilemma for faculty members at all stages of their careers, not only newly hired or graduated PhDs (Huston, 2009), it is thus important for academics in general to break away from the perception that lecture-based teaching is more comfortable.

\section{Laura Vang Rasmussen is a postdoctoral research fellow at the School of Natural Resources \& Environment, University of Michigan. She holds a PhD in geography from University of Copenhagen. Her research and teaching interests lie at the interface of human and environmental systems - mainly on issues related to land use changes, ecosystems and rural livelihoods.}

\section{Litterature}

Dahl, B. and Troelsen, R. (2013). Forelæsning. I Universitetspædagogik. Red. Rienecker L., Jørgensen, P., Dolin, J., Ingerslev, G. Samfundslitteratur 2013. DeHann, R. 2005. The Impending Revolution in Undergraduate Science Education. Journal of Science Education and Technology, Vol. 14 (2): 253-259.

Huston, T. 2009. Teaching what you don't know. Harvard University Press Merrill, D. 2012. The Myth of Teaching What You Don't Know. Perspectives. Middendorf, J. and Kalish, A. 1996. The 'Change-Up' in Lectures. The National Teaching \& Learning Forum (5), No. 2.

Nickerson, S. 2008. Role-Play: An Often Misused Active Learning Strategy. Essays on teaching Excellence. Toward the best in the Academy 19(5).

Trigwell, K., Prosser, M., and Waterhouse, F. 1999. Relations between teachers' approaches to teaching and students' approaches to learning. Higher Education 37: 57/70. Kluwer Academic Publisher 